\title{
Interobserver Variability and Stiffness Measurements of Normal Lacrimal Gland in Healthy People Using Shear Wave Elastography
}

\author{
Mahinur Cerit $\mathbb{D}$, Halit Nahit Sendur (10) \\ Department of Radiology, Gazi University School of Medicine, Ankara, Turkey
}

ORCID iDs of the authors: M.C. 0000-0003-2878-6052; H.N.Ș. 0000-0003-1690-2538.

Cite this article as: Cerit M, Șendur HN. Interobserver Variability and Stiffness Measurements of Normal Lacrimal Gland in Healthy People Using Shear Wave Elastography. Cyprus J Med Sci 2021; 6(I): 93-8.

\section{BACKGROUND/AIMS}

To determine a reference data set for stiffness values of normal lacrimal gland using shear wave elastography and to evaluate the interobserver variability of these measurements.

\section{MATERIAL and METHODS}

A total of 50 participants (bilaterally 100 glands) comprising 25 females and 25 males, aged between 19 and 58 years, were included in this prospective study. For each participant, we evaluated both lacrimal glands using grayscale and shear wave elastography, and the relationships with sex, age, and body mass index were determined. All lacrimal glands were evaluated by 2 independent observers blinded to each other.

\section{RESULTS}

The mean stiffness values of lacrimal glands for the 2 observers were $6.17 \pm 2.94 \mathrm{kPa}$ and $6.00 \pm 3.10 \mathrm{kPa}$, respectively. In terms of stiffness values, there were no significant differences between the left and right lacrimal glands and between sexes ( $p>$.05). Age exhibited a weak correlation with stiffness values $(r=0.280, p=.005 ; r=0.284, p=.004)$. The intraclass correlation coefficient for the interobserver variability of the shear wave elastography measurements was 0.948 ( $95 \%$ confidence interval: 0.924-0.965).

\section{CONCLUSION}

The lacrimal gland can be quantitatively evaluated using shear wave elastography. Normal shear wave elastography values for the lacrimal gland in the healthy population included in this study were estimated to be $6.17 \pm 2.94 \mathrm{kPa}$. Operator dependency of this method is low, and interobserver compliance is high. The standard stiffness values of the normal lacrimal gland obtained using shear wave elastography in this study may be used as reference data to distinguish the healthy tissues from the pathological tissues.

Keywords: Lacrimal gland, elastography, interobserver variability, ultrasound imaging

\section{INTRODUCTION}

The function of the lacrimal gland includes moistening of the cornea by producing tears. As the lacrimal gland contains both epithelial and lymphoid tissue, various pathologies are observed. However, the clinical presentation of lacrimal gland pathologies is nonspecific, and exophthalmos, palpebral enlargement, or deviation of the eye are common clinical findings (I). Inflammatory disease of the lacrimal gland can manifest as acute and chronic dacryoadenitis and as an inflammatory pseudotumor (2). Acute dacryoadenitis may be of bacterial or viral origin, is more common in children than in adults, and may develop in young people owing to trauma. Chronic dacryoadenitis can develop after an acute infection. It has been reported in sarcoidosis, Mikulicz syndrome, sclerosing pseudotumors, thyroid ophthalmopathy, and Wegener granulomatosis. In Siögren syndrome, the lacrimal glands increase in size owing to lymphocytic infiltration of the gland tissue. In half of the patients with Siögren syndrome, the development of connective tissue diseases, such as rheumatoid arthritis, systemic lupus erythematosus, scleroderma, or polymyositis, has been reported $(3,4)$. Additionally, the development of various benign or malignant neoplasms has also been documented.

The clinical history, symptoms, radiological imaging, and histopathological evaluation should be considered in combination for the diagnosis and treatment of lacrimal gland lesions (4). Computed tomography (CT) or magnetic resonance 
imaging (MRI) provides clear information by localizing ambigvous clinical features of the lacrimal gland and by aiding the precise determination of the extent and nature of the disease (I). Although several diseases affecting the lacrimal gland and fossa can be diagnosed specifically by adopting imaging methods, it is often difficult to distinguish each disease individually based on imaging features (2). Compared to CT and MRI that demonstrate higher sensitivity in a detailed assessment of the lacrimal gland, performance of sonography, which is cost-effective and requires a shorter duration, may be more practical in daily clinical practice. Owing to the superficial anatomy of the lacrimal gland, ultrasonography (US) can be conducted reasonably with simplicity and efficiency. Nevertheless, US is an operator-dependent technique, and intraobserver and interobserver variabilities remain a typical issue (5). Lacrimal gland US is less conducted in clinical practice. The superficial location in the superolateral part of the orbit permits the evaluation under favorable conditions, as the gland is recognized as a small hypoechoic, homogenous area (6).

Ultrasound elastography is a noninvasive method utilized to evaluate the stiffness of soft tissue, and it aids the determination of elastic properties of different tissues. Shear wave elastography (SWE) is performed to evaluate tissue elasticity in a quantitative manner. In recent years, the usage of SWE has gained considerable attention owing to the ease of applicability and less operator dependence. The elasticity is defined as elasticity modulus (or Young's modulus), measured in kilopascals ( $\mathrm{kPa})$, or as shear wave velocity, measured in meters per second $(\mathrm{m} / \mathrm{s})$. For the diagnosis and treatment of a variety of diseases, measurements of tissue elasticity may be performed $(7,8)$.

Consequently, normal elastic values for the lacrimal gland may be an indicator for the diagnosis of inflammatory diseases such as Siögren syndrome, infectious diseases such as dacryoadenitis, and neoplastic diseases such as pleomorphic adenoma (9). Various values may be provided by conducting measurements using different equipment and techniques (I0, II). Furthermore, with respect to age or body mass index (BMI), the reference values for the same tissue may differ $(12,13)$. In the existing literature, there are studies documenting the reference values of different tissues (e.g., thyroid, breast, muscle, tendon, liver, spleen, and kidney) using various technologies that use acoustic radiation force impulse, strain elastography or SWE techniques (14-18). The applicability of SWE in evaluating the lacrimal gland remains unclear, mainly owing to the availability of insufficiently reported data. To the best of our knowledge, thus far, normal 2-dimensional (2D)-SWE elasticity values for the lacrimal gland

\section{Main Points:}

- Shear wave elastography (SWE) is a reproducible imaging method for the assessment of lacrimal gland elasticity.

- The SWE measurements of the normal lacrimal gland may be used as reference data to discern healthy from abnormal parenchyma.

- In terms of stiffness values, there were no significant differences between the left and right lacrimal glands and between sexes. in healthy people were recently published in a single study (19). As SWE measurements can be used to demonstrate variabilities among vendors, the measurement of the elasticity of lacrimal glands using devices obtained from different vendors will be useful (20).

The primary aim of our study was to define elasticity values using SWE for the lacrimal glands in healthy adults and to evaluate the impact of several factors, such as sex, age, BMl, and the laterality on SWE measurements. Additionally, the study was aimed to evaluate the interobserver variability for SWE measurements.

\section{MATERIAL and METHODS}

\section{Study Design}

This prospective study was approved by a local clinical research ethics committee. Informed consent was obtained from all individuals who agreed to participate in the study. A total of 50 normal healthy adults (age range: 19-58 years; mean age: $35.26 \pm 10.05$ years) who agreed to participate in the study, comprising 25 men and 25 women, were included in the study. B-mode US followed by SWE was used for investigation of the lacrimal gland of all participants. Adults with no lacrimal gland pathology, with no medical history, and without inflammatory diseases that might influence the lacrimal gland were included in the study. Exclusion criteria were as follows: the presence of heterogeneous gland parenchyma as per grayscale US evaluation; age <18 years; refusal to adequately cooperate; refusal to participate in the study; presence of thyroid ophthalmopathy; occurrence of fever during the assessment; presentation of trauma, tumor, and a history of chronic inflammatory disease; usage of contact lenses; and a history of lacrimal gland surgery. Of the 53 normal healthy individuals who agreed to participate in the study, a total of 3 patients with heterogeneous gland parenchyma, a history of ocular surgery, and a history of trauma were excluded from the study. Demographic data (age, sex, weight, and height) were noted. BMls of all participants were calculated $\left(\mathrm{kg} / \mathrm{m}^{2}\right)$. For all cases included in the study, images of appreciable quality were obtained and techniques were performed appropriately.

\section{Ultrasonography and Shear Wave Elastography Examination}

SWE measurements were performed on the same day by 2 radiologists possessing 5 and 6 years of elastography experience, respectively. Observer I performed a B-mode US and used the 2D-SWE imaging technology to quantify the stiffness values $(\mathrm{kPa})$ of all participants consecutively. Immediately after completion of the first evaluation, observer 2 performed only an elastographic assessment of all lacrimal glands. All measurements were obtained using LOGIQ S8 (GE Healthcare Systems, Waukesha, WI, USA) with a 9-MHz linear probe. The observers were blinded to their measurement results. All participants were assessed in the supine position, with their heads turned to the opposite side. The participants were advised to breathe normally with eyes closed. The glands were assessed in longitudinal and transverse scans, but the measurements were performed in the transverse plane (Figure I). To better evaluate the area of the lacrimal glands, the ultrasound focus was adjusted. For conducting 2D-SWE evaluation, an adequate quantity of ultrasound gel was used, and no pressure was applied on the ex- 

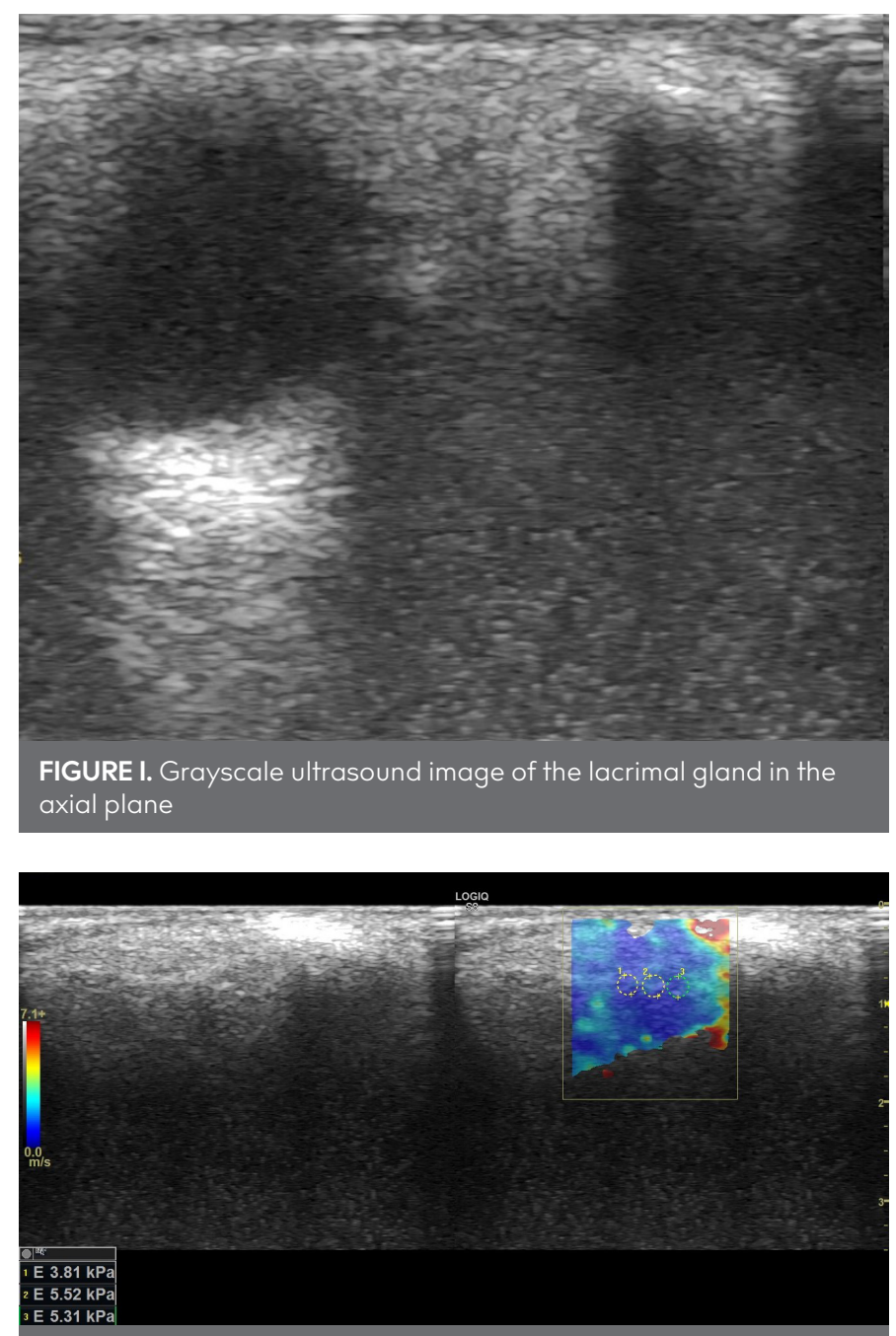

FIGURE 2. SWE measurements of the lacrimal gland were completed using a circular ROI that focused on the homogeneous parenchyma. The 2D-SWE map (right side) and grayscale image (left side) are shown. A total of 3 valid measurements were obtained. 2D-SWE: 2-dimensional shear wave elastography; ROI: region of interest

TABLE I. The Demographic Characteristics of the Participants

$\begin{array}{lc}\text { Variables } & \text { Participants }(\mathbf{n}=50) \\ \text { Age (years) } & 32.5 \text { (min-max: 19-58) } \\ \text { Gender (female/male) } & 25 / 25 \\ \text { Body mass index }\left(\mathrm{kg} / \mathrm{m}^{2}\right) & 24.77 \pm 3.08(18.6-30.9)\end{array}$

Data are expressed as mean \pm standard deviation (for normal distributions) or median (min-max) (for non-normally distribution). Max: maximum; min: minimum.

amined tissues. We used the presetting for examination of small sections. For obtaining measurements, we used the elasticity modulus (Young's modulus E). As the lacrimal gland is a small, lobulated, tear-shaped organ, the middle of the lacrimal gland was selected as the region of interest (ROI) to ensure that no measurements were acquired from extraglandular structures. A 2-mm diameter circular ROI was used, and three valid measurements were obtained (Figure 2) (19). All images were saved for further analysis. Participants were divided into 2 subgroups according to their ages ( $<40$ and $\geq 40$ years)

\section{Statistical Analysis}

The Statistical Package for the Social Sciences, version 22.0, software for Windows (IBM SPSS Corp.; Armonk, NY, USA) was used for statistical analyses. The descriptive statistics of the data are presented as mean, standard deviation, median, minimum, and maximum values. The distribution of variables was analyzed using the Kolmogorov-Smirnov test. Owing to the non-normal distribution of lacrimal gland stiffness values, the stiffness valves were compared by performing the Mann-Whitney $U$ test. For correlation analysis, Spearman's coefficient (with a 2-tailed test) was used. The numerical values obtained by using Spearman's correlation coefficient were evaluated as follows: $r$ of 0-0.19 was regarded as very weak, $r$ of 0.2-0.39 was regarded as weak, $r$ of 0.40-0.59 was regarded as moderate, $r$ of 0.6-0.79 was regarded as strong, and $r$ of 0.8-I was regarded as a very strong correlation. $\alpha=0.05$ was set as the significance level. Interobserver variability was evaluated using Bland-Altman plots; the mean difference between the 2 observers and the 95\% limits of agreement were analyzed. Paired $t$-test was used to determine the absolute valves for interobserver variability. Interobserver variability was also evaluated by using the intraclass correlation coefficient (ICC). The numerical values obtained by using ICC were evaluated as follows: <0.5 indicating poor, 0.5-0.75 indicating moderate, 0.750.90 indicating good, $>0.9$ indicating excellent agreement (2I). A $P$-value $<.05$ was considered significant.

\section{RESULTS}

Table I presents the demographic data of the participants. The mean age of the participants was 35.4 I (range: 19-58) years. All lacrimal glands exhibited normal homogeneous parenchyma with flat contours. Pathological sonographic findings suggestive of inflammatory diseases were not obtained for any participant. The mean stiffness values of lacrimal glands as assessed by the 2 observers were estimated to be $6.17 \pm 2.94 \mathrm{kPa}$ and $6.00 \pm 3.10 \mathrm{kPa}$, respectively.

SWE measurements of the lacrimal gland according to laterality, sex, and age groups are presented in Table 2. Comparison of the SWE parameters revealed no significant differences between the left and right lacrimal glands between sexes ( $p>05$ ). For observer l, the median stiffness values of lacrimal glands for participants aged $<40$ years and those aged $\geq 40$ years were 6.89 (minimum-maximum values: I.54-13.50) kPa and 3.79 (minimum-maximum values: 1.56-13.05) kPa, respectively. For observer 2 , the median stiffness values of lacrimal glands for participants aged $<40$ years and those aged $\geq 40$ years were 6.75 (minimum-maximum values: I.43-12.93) $\mathrm{kPa}$ and 4.08 (minimum-maximum: I.5I-15.20) kPa, respectively. There was a significant difference in stiffness measurements between participants aged $<40$ years and those aged above 40 years (observer I: $p=.006$; observer 2: $p=.007$ ).

In the assessment conducted by both observers, BMI showed no significant correlation with parenchyma stiffness (observer l: $p=.607$; observer 2: $p=.570$ ). Age exhibited a weak negative correlation with parenchyma stiffness (observer $\mathrm{I}: \mathrm{r}=-.280, p=.005$; observer 2: $r=-.284, P=.004$ ) (Figure 3).

The ICC for the interobserver variability of the SWE measurements was 0.948 ( $95 \%$ confidence interval: 0.924-0.965). Figure 4 presents Bland-Altman plots of pairs of SWE measurements showing the $95 \%$ limits of agreement and the median of dif- 

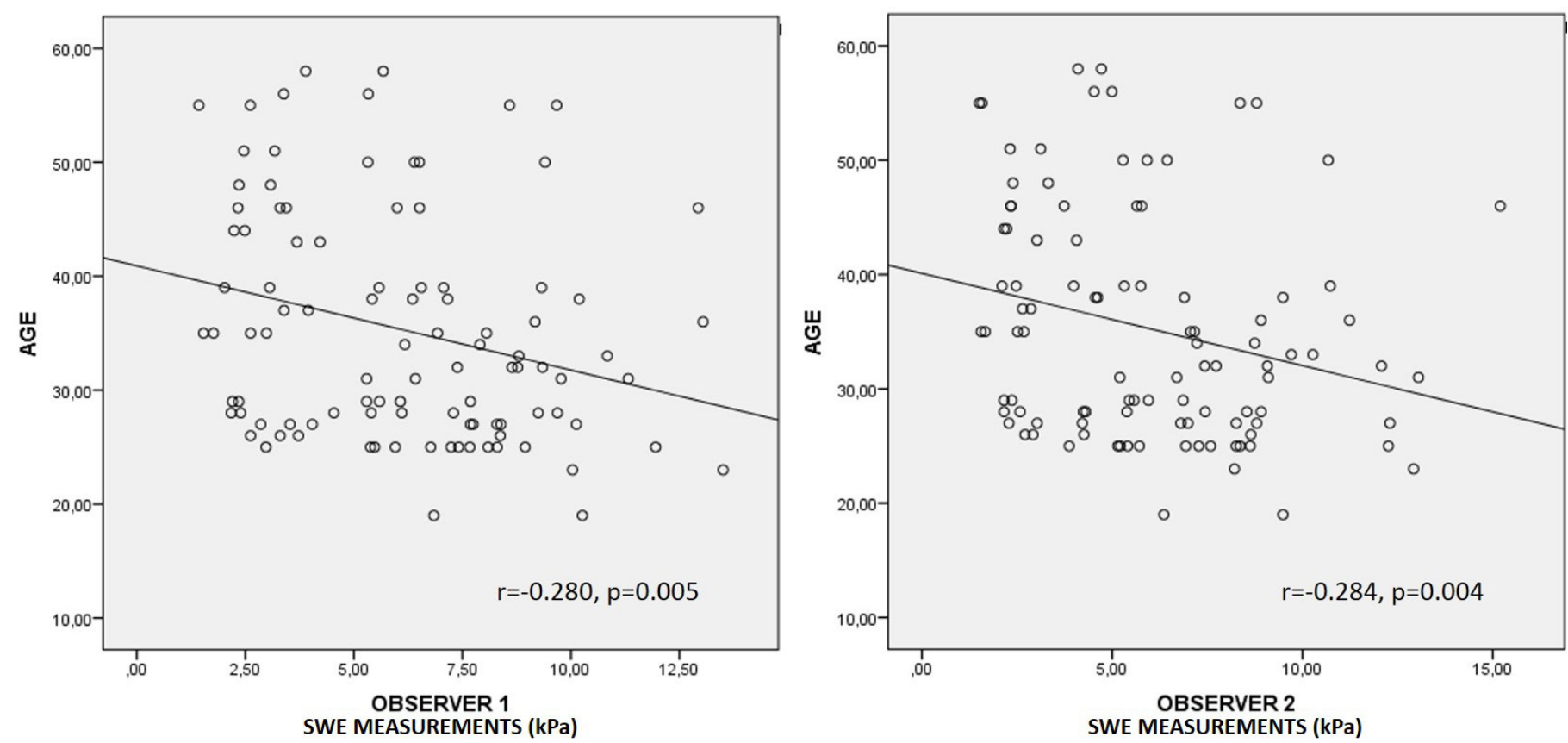

FIGURE 3. Scatterplots showing a weak negative correlation between shear wave elastography measurements and age

TABLE 2. Shear Wave Elastography Measurements of Lacrimal Gland According to Laterality, Gender, and Age Groups

\begin{tabular}{|lccc|}
\hline & Right $(\mathbf{n}=\mathbf{2 5})$ & Left $(\mathbf{n}=\mathbf{2 5})$ & $\mathbf{p}$ \\
\hline Observer I & $6.14(1.43-13.50) \mathrm{kPa}$ & $6.21(2.20-10.84) \mathrm{kPa}$ & .815 \\
Observer 2 & $5.24(1.56-15.20) \mathrm{kPa}$ & $5.86(1.51-12.30) \mathrm{kPa}$ & .942 \\
& Female $(\mathbf{n}=\mathbf{5 0})$ & Male $(\mathbf{n}=\mathbf{5 0})$ & \\
\hline Observer I & $6.66(1.54-13.50) \mathrm{kPa}$ & $5.53(1.43-11.32) \mathrm{kPa}$ & .363 \\
Observer 2 & $5.76(1.56-15.20) \mathrm{kPa}$ & $5.34(1.51-13.05) \mathrm{kPa}$ & .420 \\
& Aged < $\mathbf{4 0}$ years $(\mathbf{n}=\mathbf{7 4})$ & Aged $\geq \mathbf{4 0}$ years $(\mathbf{n}=\mathbf{2 6})$ & \\
\hline Observer I & $6.89(1.54-13.50) \mathrm{kPa}$ & $3.79(1.43-12.93) \mathrm{kPa}$ & .006 \\
Observer 2 & $6.75(1.56-13.05) \mathrm{kPa}$ & $4.08(1.51-15.20) \mathrm{kPa}$ & .007 \\
\hline *P<.05 has been considered statistically significant (two-tailed test) & \\
\hline
\end{tabular}

ferences for interobserver variability. The mean interobserver difference of SWE measurements was 0.17 . The range of measurement error expressed as $95 \%$ limits of agreement was \pm 1.88 . There was no significant difference between absolute values of SWE measurements $(P=.081)$.

\section{DISCUSSION}

In this study, we defined normal values for lacrimal gland stiffness measurements by performing SWE in adult healthy participants, and we evaluated the influence of several factors, such as sex, age, BMI, and the laterality on SWE-based imaging valves. In terms of SWE measurements, there were no significant differences between the left and right lacrimal glands and between sexes. Age exhibited a weak correlation with stiffness values. Additionally, we assessed the interobserver variability of SWE measurements, and excellent interobserver reliability was demonstrated.

Undoubtedly, the presence of reference values for a measured parameter is necessary to discern pathological cases from

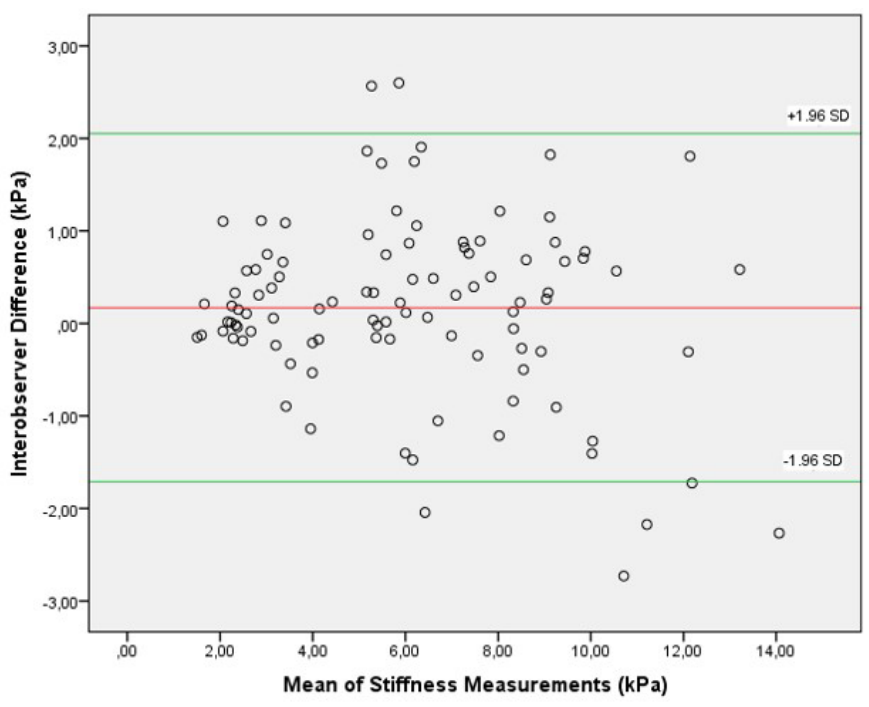

FIGURE 4. Bland-Altman plots of stiffness measurements conducted and obtained by 2 observers. The difference in stiffness values between observers I and 2 is plotted against the mean stiffness values obtained by 2 observers. The red line represents the mean difference of all measurements $(n=100)$, and the green lines represent $95 \%$ Bland-Altman limits of agreement (mean \pm 1.96 SD). SD:

standard deviation

healthy ones via implementation of a diagnostic method. Identification of reference values is the critical initial process for the determination of a diagnostic technique and for the definition of values for investigation of several types of diseases. This pilot study represents the first attempt to identify the reference values for the lacrimal gland parenchyma in healthy patients. In the study reported by Bădărînză et al. (19), in which the authors measured the 2D-SWE values of the lacrimal gland using Supersonic Imagine Aixplorer Ultimate device in healthy adults, normal values were found to be $9.47 \pm 2.1$ (4.8-15.9). In contrast, in the 
present study conducted using the LOGIQ S8 (GE Healthcare Systems) device, normal 2D-SWE values of the lacrimal gland were estimated to be $6.17 \pm 2.94 \mathrm{kPa}$ (observer I) and $6.00 \pm 3.10 \mathrm{kPa}$ (observer 2). The main differences might be attributable to the machines and converters used. It has been reported that shear wave velocities exhibit a dependency on excitation frequencies and that devices obtained from different vendors may operate at different frequencies (7). Moreover, in a phantom study, Shin et al. (23) have shown that shear wave velocities are different among different ultrasound devices and among different transducers. Considering that SWE measurements may demonstrate significant variabilities among the devices manufactured by vendors, the application of different ultrasound devices for the conduction of studies may be the most plausible explanation for the obtainment of discordant results (20). Thus, additional studies are warranted for the establishment of exchangeable normal values.

In this study, factors such as sex, laterality, and BMl, that were hypothesized to affect parenchymal elasticity, exerted no effect on reference SWE values of the lacrimal glands. These results were in line with those reported by a previous study (19) and showed that the reference values for lacrimal glands could be reproducible and might be beneficial for the conduction of future studies.

The age-related alterations of the lacrimal gland comprise improved fat content in epithelial secretory cells and glandular tissue, glandular parenchymal atrophy, and increased interstitial connective tissue (22). In our study, a weak negative correlation was observed between age and elasticity values. Additionally, according to the age groups ( $<40$ years, $\geq 40$ years), the measurement of SWE was found to decrease with the age $(P<.05)$. These results are predictable for the lacrimal gland, whose age-related atrophy is associated with an increase in the fatty component. In a study conducted by Herman et al. (17) involving adults (aged 21-91 years), normal elasticity values were determined for the salivary glands, thyroid gland, cervical lymph nodes, and sternocleidomastoid and masseter muscles, and a mild decrease in elasticity was observed with increasing age (17). However, in the study reported by Bădărînză et al. (19), a statistically significant difference was not found between age groups in terms of 2D-SWE measurements. Studies with a wider age range and more participants are warranted for further clarification.

Interobserver and intraobserver variabilities are an important aspect of radiological evaluations. Additionally, weak reproducibility is one of the traditional limitations in ultrasonographic evaluations. There are several studies in the literature documenting applications of SWE for investigation of the liver, thyroid, breast, prostate, salivary glands, and cervical lymph nodes, and in these studies, limited or negligible limitations were found in technical performance and reproducibility in SWE measurements $(16,24-29)$. In the present study, as evidenced by both the ICC and the Bland-Altman analysis, the interobserver agreements were high. This study is the first to evaluate interobserver variability in the assessment of lacrimal gland using 2D-SWE, and our results showed that 2D-SWE might be a beneficial, noninvasive diagnostic method with high reproducibility that could be useful for the evaluation of lacrimal glands.
This study has certain limitations. First, one of the most important limitations of this study is that the study cohort was heterogeneous and small. Therefore, the results of this study should be verified through studies using a large-sized cohort. Second, the lack of available software designed and developed specifically for the examination of the lacrimal glands may be considered another drawback of the present study. Third, the intraobserver variability was not assessed. Future studies that will focus on the evaluation of both intra and interobserver variabilities are necessary. Fourth, the lack of histopathological correlation is a limitation of this study. In contrast, a histopathological correlation could not be performed because the study population comprised normal healthy individuals and because the lacrimal gland biopsy was an invasive and challenging procedure. Finally, we were unaware of the time between the participant's last crying and US assessment and did not confirm whether this could have any impact on 2D-SWE results. To the best of our knowledge, no sufficient information is present in the literature on this issue, and comprehensive studies are warranted. Similarly, a lack of control of the potential confounders by variables, such as environmental conditions (climate, moisture, or the prevailing atmospheric conditions) or age-related dry eye development, might have also exerted effects on the lacrimal gland stiffness (30).

SWE is a reproducible imaging method used for the assessment of lacrimal gland elasticity. The SWE measurements of the normal lacrimal gland may be used as reference data to discern healthy parenchyma from abnormal parenchyma. However, further studies are necessary to validate its utility before the application of this technology in routine clinical cases.

Ethics Committee Approval: Ethics committee approval was received for this study from the ethics committee of Gazi University Clinical Research Ethics Committee (Approval Date/Number: 07.12.2020/830).

Informed Consent: Informed consent was obtained from all individuals who agreed to participate in the study.

Peer-review: Externally peer-reviewed.

Author contributions: Concept - M.C.; Design - M.C.; Supervision - H.N.Ș.; Resource - M.N.C., H.N.Ș.; Materials - M.C., H.N.S.; Data Collection and/or Processing - M.N.C., H.N.Ș; Analysis and/or Interpretation - M.C.; Literature Search - M.C.; Writing - M.C.; Critical Reviews - H.N.Ș.

Conflict of Interest: Authors have no conflicts of interest to declare.

Financial Disclosure: The authors declared that this study has received no financial support.

\section{REFERENCES}

I. Hughes GK, Miszkiel KA. Imaging of the lacrimal gland. Semin UItrasound CT MR 2006; 27(6): 476-9I. [Crossref]

2. Jung WS, Ahn KJ, Park MR, Kim JY, Choi JJ, Kim BS, et al. The radiological spectrum of orbital pathologies that involve the lacrimal gland and the lacrimal fossa. Korean J Radiol 2007; 8(4): 336-42. [Crossref]

3. Bilgili Y, Taner P, Unal B, Simsir I, Kara SA, Bayram M, et al. Doppler sonography of the normal lacrimal gland. J Clin Ultrasound 2005; 33(3): 123-6. [Crossref]

4. Lorenzano D, Rose GE. The "Wedge Sign": An Imaging Sign for Aggressive Lacrimal Gland Disease. Ophthalmology 2017; 124(7): 10813. [Crossref] 
5. Lecler A, Boucenna M, Lafitte F, Koskas P, Nau E, Jacomet PV, et al. Usefulness of colour Doppler flow imaging in the management of lacrimal gland lesions. Eur Radiol 2017; 27(2): 779-89. [Crossref]

6. Giovagnorio F, Pace F, Giorgi A. Sonography of lacrimal glands in Siögren syndrome. J Ultrasound Med 2000; 19(8): 505-9. [Crossref]

7. Sigrist RMS, Liau J, Kaffas AE, Chammas MC, Willmann JK. Ultrasound Elastography: Review of Techniques and Clinical Applications. Theranostics 2017; 7(5): 1303-29. [Crossref]

8. Taljanovic MS, Gimber LH, Becker GW, Latt LD, Klauser AS, Melville DM, et al. Shear-Wave Elastography: Basic Physics and Musculoskeletal Applications. Radiographics 2017; 37(3): 855-70. [Crossref]

9. Caliskan E, Ozturk M, Bayramoglu Z, Comert RG, Adaletli I. Evaluation of parotid glands in healthy children and adolescents using shear wave elastography and superb microvascular imaging. Radiol Med 2018; 123(9): 710-8. [Crossref]

10. Hu X, Liu Y, Qian L (2017) Diagnostic potential of real-time elastography (RTE) and shear wave elastography (SWE) to differentiate benign and malignant thyroid nodules: a systematic review and meta-analysis. Medicine (Baltimore) 96: e8282. https://doi. org/10.1097/MD.0000000000008282

II. Mulazzani L, Salvatore V, Ravaioli F et al (2017) Point shear wave ultrasound elastography with Esaote compared to realtime 2D shear wave elastography with supersonic imagine for the quantifcation of liver stifness. J Ultrasound 20: 213-25. https://doi.org/10.1007/ s40477-017-0260-7

12. Palabiyik FB, Inci E, Turkay R, Bas D (2017) Evaluation of liver, kidney, and spleen elasticity in healthy newborns and infants using shear wave elastography. J Ultrasound Med 36: 2039-45. [Crossref]

13. Bailey SS, Youssf M, Patel M, Hu HH, Shaibi GQ, Towbin RB (2017) Shear-wave ultrasound elastography of the liver in normal-weight and obese children. Acta Radiol 58: 15II-8. [Crossref]

14. Șendur HN, Gültekin S, Salimli L, Cindil E, Cerit M, Șendur AB. Determination of Normal Breast and Areolar Skin Elasticity Using Shear Wave Elastography. J Ultrasound Med 2019; 38(7): 1815-22. [Crossref]

15. Aksoy S, Colak C, Nalbant MO, Turkay R, Erdil I, Hocaoglu E, et al. Comparison of elasticity values of the right lobe of the liver of normal weight and morbidly obese Turkish patients. Niger J Clin Pract 2017; 20: 542-4. [Crossref]

16. Șendur HN, Cindil E, Cerit MN, Kılıç P, Gültekin II, Oktar SÖ. Evaluation of effects of aging on skeletal muscle elasticity using shear wave elastography. Eur J Radiol 2020; 128: 109038. [Crossref]

17. Herman J, Sedlackova Z, Vachutka J, Furst T, Salzman R, Vomacka $J$. Shear wave elastography parameters of normal soft tissues of the neck. Biomed Pap Med Fac Univ Palacky Olomouc Czech Repub 2017; 161: 320-5. [Crossref]

18. Mantsopoulos K, Klintworth N, Iro H, Bozzato A. Applicability of shear wave elastography of the major salivary glands: values in healthy patients and efects of gender, smoking and pre-compression. Ultrasound Med Biol 20I5; 4I: 23I0-8. [Crossref]
19. Badarinza M, Serban O, Maghear L, Bocsa C, Micu M, Porojan MD, et al. Multimodal ultrasound investigation (grey scale, Doppler and 2D-SWE) of salivary and lacrimal glands in healthy people and patients with diabetes mellitus and/or obesity, with or without sialosis. Med Ultrason 2019; 2I(3): 257-64. [Crossref]

20. Lee SM, Chang W, Kang HJ, Ahn SJ, Lee JH, Lee JM. Comparison of four different Shear Wave Elastography platforms according to abdominal wall thickness in liver fibrosis evaluation: a phantom study. Med Ultrason 2019; 21(I): 22-9. [Crossref]

21. Armitage P, Berry G. In: Statistical Methods in Medical Research, 3rd edn. Oxford: Blackwell Scientific Publications, 1994:312-41. 22Koo TK, Li MY. A Guideline of Selecting and Reporting Intraclass Correlation Coefficients for Reliability Research. J Chiropr Med 2016; 15(2): 155-63. doi: 10.1016/i.jcm.2016.02.012. Erratum in: J Chiropr Med 2017; 16(4): 346. [Crossref]

22. Conrady CD, Joos ZP, Patel BC. Review: The Lacrimal Gland and Its Role in Dry Eye. J Ophthalmol 2016; 2016: 7542929. [Crossref]

23. Shin HJ, Kim MJ, Kim HY, Roh YH, Lee MJ. Comparison of shear wave velocities on ultrasound elastography between different machines, transducers, and acquisition depths: a phantom study. Eur Radiol 2016; 26(10): 3361-7. [Crossref]

24. Beland MD, Brown SF, Machan JT, Taliano RJ, Promrat K, Cronan JJ. A pilot study estimating liver fibrosis with ultrasound shear-wave elastography: does the cause of liver disease or location of measurement affect performance? AJR Am J Roentgenol 2014; 203(3): W267-73. [Crossref]

25. Fukuhara T, Matsuda E, Fujiwara K, Tanimura C, Izawa S, Kataoka H, et al. Phantom experiment and clinical utility of quantitative shear wave elastography for differentiating thyroid nodules. Endocr $\mathrm{J}$ 2014; 6I(6): 615-2I. [Crossref]

26. Au FW, Ghai S, Moshonov H, Kahn H, Brennan C, Dua H, et al. Diagnostic performance of quantitative shear wave elastography in the evaluation of solid breast masses: determination of the most discriminatory parameter. AJR Am J Roentgenol 2014; 203(3): W32836. [Crossref]

27. Woo S, Kim SY, Cho JY, Kim SH. Shear wave elastography for detection of prostate cancer: a preliminary study. Korean J Radiol. 2014; 15(3): 346-55. doi: 10.3348/kir.2014.15.3.346. Erratum in: Korean J Radiol. 2015; 16(6): 1373. [Crossref]

28. Bhatia KS, Cho CC, Tong CS, Lee YY, Yuen EH, Ahuja AT. Shear wave elastography of focal salivary gland lesions: preliminary experience in a routine head and neck US clinic. Eur Radiol 2012; 22(5): 957-65. [Crossref]

29. Choi YJ, Lee JH, Lim HK, Kim SY, Han MW, Cho KJ, et al. Quantitative shear wave elastography in the evaluation of metastatic cervical lymph nodes. Ultrasound Med Biol 2013; 39(6): 935-40. [Crossref]

30. Dartt DA. Neural regulation of lacrimal gland secretory processes: relevance in dry eye diseases. Prog Retin Eye Res 2009; 28(3): 155-77. [Crossref] 